\title{
EARLY EFFECTS OF RIGHT VENTRICULAR VOLUME OVERLOAD ON VENTRICULAR PERFORMANCE AND $\beta$-ADRENERGIC SIGNALING
}

Ashish S. Shah, MD

B. Zane Atkins, MD, Jonathan A. Hata, BA Oliver Tai, BS

Alan P. Kypson, MD

R. Eric Lilly, MD

Walter J. Koch, PhD

Donald D. Glower, MD
Objective: Right ventricular dysfunction is a poorly understood but persistent clinical problem. This study was undertaken to evaluate ventricular performance and $\beta$-adrenergic receptor signaling in a tricuspid regurgitation model of right ventricular overload.

Methods: Seventeen dogs were chronically instrumented with epicardial dimension transducers. By means of the shell-subtraction model, right ventricular pressure-volume relationships were evaluated in normal and right ventricular overload states. Right ventricular chamber performance was quantified by the stroke work at an end-diastolic volume relationship.

Results: Right ventricular volume overload caused a $28 \% \pm 11 \%$ and $31 \% \pm$ $9 \%$ decline in chamber performance acutely and at 1 week, respectively, whereas end-diastolic volume increased from $45 \pm 21$ to $60 \pm 30 \mathrm{~mL}(P=$ .019). $\beta$-Adrenergic receptor signaling in myocardial samples was assessed, examining adenylyl cyclase and G-protein-coupled receptor kinase activity. Stimulated adenylyl cyclase activity significantly decreased, and G-protein-coupled receptor kinase activity significantly increased in both left and right ventricular samples caused by increased levels of $\beta$-adrenergic receptor kinase 1 . No change in $\beta$-adrenergic receptor density was seen at 1 week.

Conclusions: Early right ventricular overload is associated with impaired right ventricular chamber contractility, dilation, and, importantly, a biventricular alteration of $\beta$-adrenergic receptor signaling. ( $\mathrm{J}$ Thorac Cardiovasc Surg 2000;119:342-9)
A complete experimental and clinical understanding of right ventricular (RV) function remains elusive because of difficulty assessing RV volume and performance. ${ }^{1}$ Previous observations and studies support the notion that the right ventricle tolerates volume overload

From the Department of General and Thoracic Surgery, Duke University Medical Center, Durham, NC.

Presented in part at the Seventy-first Scientific Sessions of the American Heart Association, November 1998.

Supported by grants from the National Institutes of Health: HL56227 (D.D.G.), HL56205 (W.J.K.), and HL09907 (A.S.).

Received for publication Sept 22, 1999; revisions requested Nov 19, 1999; revisions received Jan 11, 2000; accepted for publication March 20, 2000.

Address for reprints: Donald D. Glower, MD, PO Box 3851, Duke University Medical Center, Durham, NC 27710 (E-mail: glowe001@mc.duke.edu).

Copyright (C) 2000 by The American Association for Thoracic Surgery

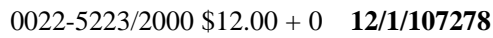

doi:10.1067/mtc. 2000.107278 well and pressure overload poorly. ${ }^{1}$ In the face of preserved ejection fraction, RV volume overload in a number of models leads to depressed left ventricular (LV) function, septal shifting, and alterations of LV loading. ${ }^{2}$ Although load-insensitive measures of contractility have been extensively applied to the left ventricle, few studies have examined RV performance in volume overload. Maughan and colleagues ${ }^{3}$ established the validity of RV pressure-volume relationships. Twenty years later, Karunanithi and colleagues ${ }^{4}$ examined a number of load-insensitive indices of ventricular function in the normal right ventricle and elegantly demonstrated the linearity of the preload recruitable stroke work (PRSW) relationship in the normal canine right ventricle, confirming its utility as a measure of RV contractility.

Alterations of $\beta$-adrenergic receptor ( $\beta$-AR) signaling have also been characterized in clinical and experimental heart failure. ${ }^{5-7} \mathrm{LV}$ and biventricular failure is associated with downregulation of $\beta$-ARs, depression of adenylyl cyclase (AC) activity, and enhanced G-protein 
receptor kinase (GRK) activity mediated through increased expression of the $\beta$-AR kinase ( $\beta$ ARK1). Similarly, studies of right heart failure have reported a decline in biventricular AC activity, ${ }^{8}$ and one report demonstrated that in experimental RV failure there is a specific decline in RV but not LV $\beta$-AR density. ${ }^{9}$ The present study was developed to assess intrinsic RV performance independently of confounding load changes and to examine global biventricular $\beta$-AR signaling abnormalities in RV dysfunction because of isolated RV volume overload.

\section{Methods}

All animals received humane care in compliance with the "Principles of Laboratory Animal Care" formulated by the National Society for Medical Research and the "Guide for the Care and Use of Laboratory Animals" prepared by the National Academy of Sciences and published by the National Institutes of Health (Department of Health and Human Services publication No. 85-23, revised 1985).

Seventeen healthy adult dogs $(22-30 \mathrm{~kg})$ were anesthetized and intubated with pentobarbital $(50 \mathrm{mg} / \mathrm{kg})$, fentanyl (200 $\mu \mathrm{g}$ ), and succinylcholine (INN: suxamethonium; $1 \mathrm{mg} / \mathrm{kg}$ ). In addition, cefazolin ( $1 \mathrm{~g})$ and iron dextran $(250 \mathrm{mg})$ were administered preoperatively. A left lateral thoracotomy was performed, and pneumatic vena caval occluders were placed around the superior and inferior venae cavae. ${ }^{10}$ The heart was then suspended in a pericardial cradle, and pulse transit ultrasonic dimension transducers were positioned across the base-apex major axis and the anteroposterior minor axis diameters of the left ventricle. In addition, transducers were placed across the septal free wall minor axis diameters of both the left and right ventricles. The septal crystal $(1.5 \mathrm{~mm}$ outer diameter) was placed through the tract of a 16-gauge needle that was introduced into the septum. All other crystals were sutured to the epicardium (Fig 1). Two silicone rubber pleural catheters were then placed, and the pericardium was left open. All hardware was tunneled though a Teflon skin button dorsal and caudal to the incision. All animals were allowed to recover for 7 to 10 days before the study. Animals were studied in the conscious state with morphine sedation $(0.7 \mathrm{mg} / \mathrm{kg}$ administered intramuscularly) while lying quietly on their right side.

Experimental protocol. Dimension transducers were coupled to a sonomicrometer (Physiologic Systems Inc, Durham, NC), and a cutdown was performed over the right external jugular vein with $1 \%$ lidocaine. A $5 \mathrm{~F}$ micromanometer (Millar Inc, Houston, Tex) was placed into the right ventricle under fluoroscopic guidance through the right jugular vein. A micromanometer was also placed in the pleural space. Autonomic attenuation was achieved with intravenous propranolol $(1 \mathrm{mg} / \mathrm{kg})$ and atropine $(0.1$ $\mathrm{mg} / \mathrm{kg}$ ) and titrated to limit heart rate variability during vena caval occlusions to less than $10 \%$. Baseline data were acquired under steady-state conditions and after rapid vena caval occlusion over 30 seconds. After baseline data acquisition, severe volume overload was created by the induction of tricuspid regurgitation (TR). TR was created by introducing a $6 \mathrm{~F}$ urologic biopsy forceps (Circon Instruments, Santa Barbara, Calif) into the right ventricle and severing chordae tendineae until 3 to $4+$ regurgitation was produced and confirmed fluoroscopically. In addition, all animals had an elevation of the right atrial $\mathrm{v}$ wave to $200 \%$ over baseline. Acute TR data were obtained after 1 hour, and the animals were allowed to recover. After 1 week of TR, animals were studied again, as described above. After completion of the study, animals were killed. The hearts were then rapidly weighed and measured, and transmural samples of the RV and LV free walls were frozen in liquid nitrogen.

Data analysis. Analog data was digitized at $200 \mathrm{~Hz}$ and analyzed on a VAX workstation (Digital Equipment Corp, Worburn, Mass) by using custom software (Physiologic Systems Inc, Durham, NC). RV chamber volume was calculated from the cardiac dimension measurements ( $a, b, c$, and d) according to an ellipsoidal shell subtraction model described previously ${ }^{4}$ and represented by the following equations:

$$
\begin{gathered}
\text { Vrv }=(\text { Vtotal }- \text { Vlv })-\text { Vrv free wall } \\
\operatorname{Vrv}=\pi / 6(a \cdot b \cdot d)-\text { Vrvfw, }
\end{gathered}
$$

where Vtotal was the total epicardial volume and Vlv was the LV epicardial volume. The RV free wall volume (Vrvfw) was determined post mortem. RV transmural pressure (P) was determined as the difference between intracavitary and pleural pressure. $\mathrm{RV} \mathrm{dP} / \mathrm{dt}$ was computed from the digital pressure waveform as a running 5-point polyorthogonal transformation. The cardiac cycle was then defined by means of $\mathrm{dP} / \mathrm{dt}$, as previously described. ${ }^{4,10}$

The RV PRSW relation was determined by linear regression of the stroke work (SW)/end-diastolic volume (EDV) relationship. ${ }^{11} \mathrm{Mw}$ and $\mathrm{Vw}$ represented the slope and $\mathrm{x}$-intercept of this linear relationship. To evaluate chamber contractility, SW at a constant EDV (SW-EDVc) was determined for each animal and condition by the following equation:

$$
\mathrm{SW}-\mathrm{EDVc}=\operatorname{Mw}(1.2 \cdot[\mathrm{Vwmax}]-\mathrm{Vw})
$$

Here, Vwmax was the largest $\mathrm{Vw}$ for the entire experiment. ${ }^{12}$

Tissue analysis. To determine whether this model of RV dysfunction leads to global $\beta$-AR signaling abnormalities, we used samples from the LV and RV free wall from 9 animals with severe TR to perform biochemical analysis. Eight animals underwent sham thoracotomy and instrumentation and composed the control group.

$\beta$-AR density and $A C$ activity. $A C$ activity and $\beta$-AR binding were performed from myocardial sarcolemmal membranes, as described previously. ${ }^{7,13}$ For AC activity, membranes (30-40 $\mu \mathrm{g}$ of protein) were incubated for 15 minutes at $37^{\circ} \mathrm{C}$ with $\alpha$-phosphorous 32 adenosine triphosphate under basal conditions or isoproterenol (INN: isoprenaline; $10^{-4}$ $\mathrm{mol} / \mathrm{L}$ ), and cyclic adenosine monophosphate was quantified. Ligand-binding assays were done in triplicate. Total $\beta$-AR 


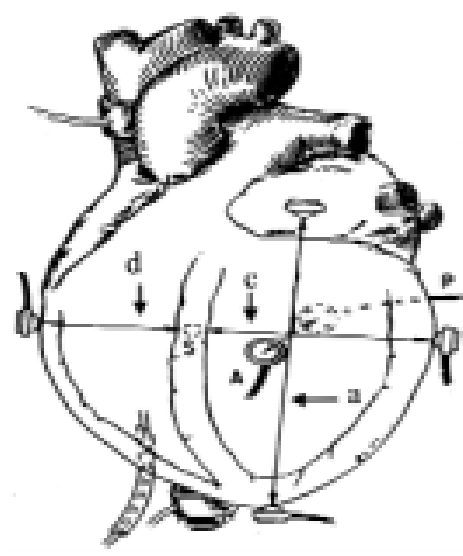

Fig 1. Schematic representation of sonomicrometric crystal positions and axes used for modeling of the RV. $a$, Base-apex major axis; $A$, anterior minor axis; $P$, posterior minor axis represented as $b$ in the model; $c$, LV free wall septum; $d, \mathrm{RV}$ free wall septum. Vena caval occluders and a silicone rubber pleural catheter is also shown.

density was determined by incubating $25 \mu \mathrm{g}$ of sarcolemmal membranes with a saturating concentration of iodine 125 cyanopindolol (300 pmol/L) and $20 \mu \mathrm{mol} / \mathrm{L}$ alprenolol to define nonspecific binding. ${ }^{13}$

GRK activity assays. Concentrated cytosolic extracts were incubated with rhodopsin-enriched rod outer segment membranes in $75 \mu \mathrm{L}$ of GRK lysis buffer, as described previously. ${ }^{13}$ Phosphorylated rhodopsin was visualized by autoradiography of dried gels, and GRK-mediated phosphate incorporation was quantified by means of a PhosphorImager system (Molecular Dynamics, Inc, Sunnyvale, Calif). ${ }^{13}$

BARK1 immunodetection. Immunodetection of myocardial levels of $\beta$ ARK1 was performed on cardiac cytosolic protein extracts after immunoprecipitation, as previously described.,13 $\beta$ ARK1 was immunoprecipitated by using $1: 2000$ of a monoclonal anti- $\beta$ ARK 1 antibody and $35 \mu \mathrm{L}$ of $50 \%$ slurry of protein A-agarose conjugate agitated for 1 hour at $4{ }^{\circ} \mathrm{C}$. The $80-\mathrm{kd} \beta A R K 1$ protein was visualized by means of standard chemiluminescence (ECL, Amersham Corp, Arlington Heights, Ill). Quantification of immunoreactive products was done by scanning the final autoradiography films and using the ImageQuant software (Molecular Dynamics).

Neuropeptide $Y$ assay. For neuropeptide $Y$ determination, tissue samples of myocardium were homogenized in radioimmunoassay buffer $(0.1 \mathrm{~mol} / \mathrm{L}$ sodium phosphate, $\mathrm{pH} 7.4$, containing $0.1 \% \quad \beta$-mercaptoethanol and $0.1 \%$ bovine serum albumin). Neuropeptide $\mathrm{Y}$ was then determined with a commercially available radioimmunoassay (Peninsula Labs, San Carlos, Calif).

Statistical analysis. Except where noted, all summary data are expressed as a mean $\pm \mathrm{SD}$. A paired Student $t$ test was used for all comparison of in vivo hemodynamic data. Oneway analysis of variance was used for all other comparisons.

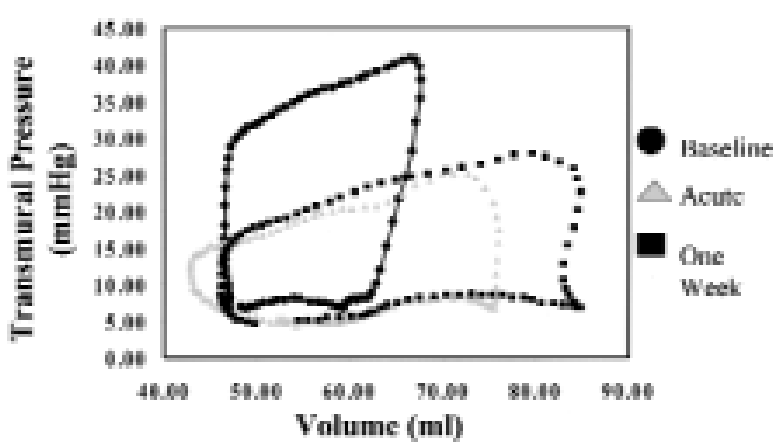

Fig 2. Representative pressure-volume loops at baseline and either acutely or after 1 week of TR for a single animal.

\section{Results}

In vivo studies. The shell-subtraction model reflected alterations of RV volume, with predictable increases in RV volume caused by volume overload (Fig 2). Acute volume overload caused significant increases in end-diastolic pressure (EDP) and EDV in the right ventricle (Table I). Subacute volume overload was characterized by persistent elevations of EDP and EDV. RV volume overload caused a depression of $\mathrm{dP} / \mathrm{dt}$ and systolic pressure acutely, with reversal at 1 week (Table I). No animal in this study showed clinical signs of RV failure, such as ascites or peripheral edema.

To evaluate RV performance, we performed a linear regression analysis on the SW/EDV relationship $(n=$ 9). SW-EDVc decreased after acute TR from $657.5 \pm$ 192 to $474.0 \pm 221$ kiloergs (kergs) $(P=.03)$. One week of TR showed a persistent depression of ventricular function at $451.6 \pm 254 \mathrm{kergs}(P=.0003$, Fig 3$)$. The volume-intercept of this relationship is unchanged acutely but appears to shift to the right after 1 week ( $P$ $=.11$, Table I). The PRSW relationship remained highly linear, with mean regression coefficients of 0.92 , 0.92 , and 0.88 for baseline and acute and subacute volume overload, respectively.

Subacute TR was not associated with significant increases in RV free wall volume compared with that found in sham-operated control animals $(38.1 \pm 4$ vs $35.9 \pm 9 \mathrm{~mL}, P=.47)$. Thus, RV volume overload was not accompanied by myocardial hypertrophy at 1 week.

$\beta$-AR signaling. Total $\beta$-AR density was unchanged between TR and control animals in both ventricles (Fig 4). However, significant depression of AC activity was seen both under basal and isoproterenol-stimulated conditions, consistent with functional uncoupling and 


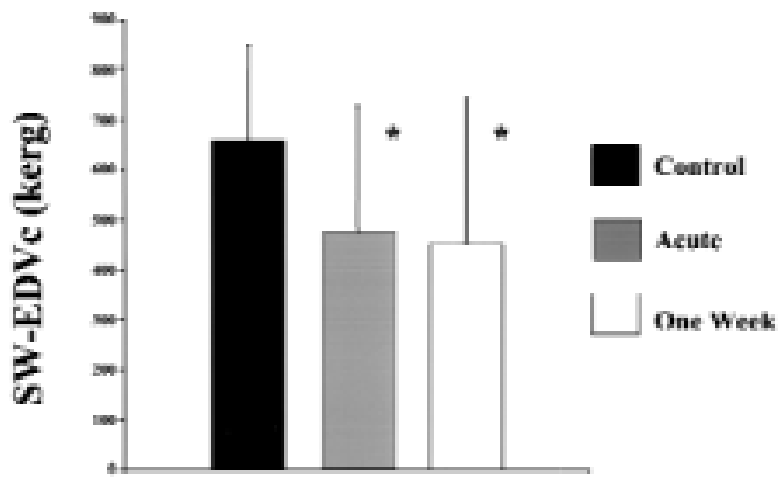

Fig 3. RV chamber performance was assessed by using the SW-EDVc. RV volume overload resulted in a sustained depression of $\mathrm{RV}$ chamber performance. ${ }^{*} P=.03$ versus baseline.

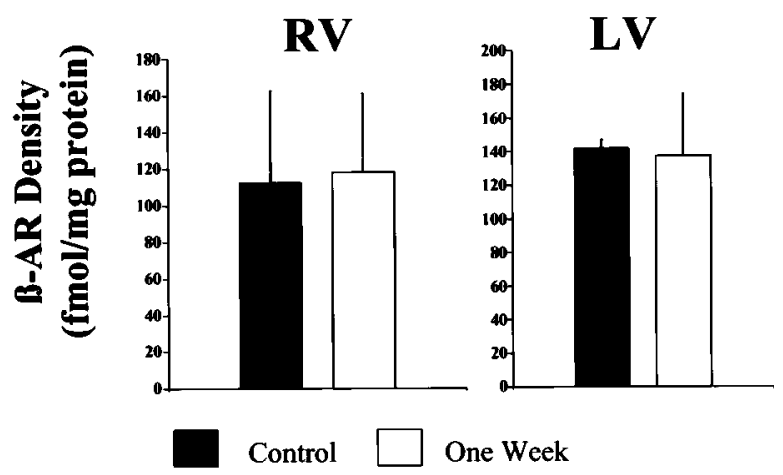

Fig 4. Total $\beta$-AR density (mean \pm SEM) in animals with TR at 1 week $(n=9)$ versus control animals $(n=8)$. No statistically significant difference was observed between each group and chamber $(P=.5)$.

Table I. Summary of RV hemodynamic parameters

\begin{tabular}{|c|c|c|c|c|c|c|c|}
\hline & $\begin{array}{l}E D V \\
(m L)\end{array}$ & $\begin{array}{c}E D P \\
(m m H g)\end{array}$ & $\begin{array}{c}S B P \\
(m m H g)\end{array}$ & $\begin{array}{c}H R \\
\text { (beats/min) }\end{array}$ & $\begin{array}{l}d P / d t \max \\
(\mathrm{mm} H g / s)\end{array}$ & $\begin{array}{c}M w \\
(k e r g / m L)\end{array}$ & $\begin{array}{l}V w \\
(m L)\end{array}$ \\
\hline Baseline & $44.7 \pm 20.9$ & $3.8 \pm 2.2$ & $29.2 \pm 4.0$ & $126.6 \pm 11.5$ & $691.0 \pm 49.8$ & $19.1 \pm 5.1$ & $24.6 \pm 10.9$ \\
\hline Acute & $60.4 \pm 30.2^{*}$ & $8.1 \pm 3.2 \neq$ & $22.5 \pm 2.1 \S$ & $122 \pm 15.7$ & $462.6 \pm 12 \pi$ & $12.6 \pm 3.7 \ddagger$ & $21.9 \pm 15.0$ \\
\hline One week & $59.8 \pm 28.9 \dagger$ & $7.88 \pm 3.6$ & $27.6 \pm 3.8$ & $125.7 \pm 22.3$ & $584.1 \pm 113$ & $15.6 \pm 4.4^{*}$ & $30.0 \pm 16.5 \#$ \\
\hline
\end{tabular}

$S B P$, systolic blood pressure; $H R$, heart rate; $M w$ and $V w$, slope and $\mathrm{x}$-intercept, respectively, of the SW/EDV relationship.

$* P=.02$ versus baseline.

$\dagger P=.033$ versus baseline.

$\ddagger P=.021$ versus baseline.

$\S P=.012$ versus baseline.

II $P=.016$ versus baseline.

$\# P=.11$ versus baseline.

Table II. AC values at baseline and after $10^{-4} \mathrm{~mol} / \mathrm{L}$ isoproterenol expressed as mean \pm SEM as a percentage of sodium fluoride $(\mathrm{NaF})(10 \mathrm{mmol} / \mathrm{L})$ values for control animals $(n=8)$ and after 1 week of TR $(n=9)$

\begin{tabular}{|c|c|c|c|c|}
\hline & \multicolumn{2}{|r|}{$L V$} & \multicolumn{2}{|r|}{$R V$} \\
\hline & Basal & Isoproterenol $\left(10^{-4} \mathrm{~mol} / \mathrm{L}\right)$ & Basal & Isoproterenol $\left(10^{-4} \mathrm{~mol} / \mathrm{L}\right)$ \\
\hline Control & $30.0 \pm 2.7$ & $35.0 \pm 1.4$ & $28.7 \pm 4.3$ & $36.6 \pm 2.4$ \\
\hline One week of TR & $19.9 \pm 1.6^{*}$ & $27.2 \pm 1.6 \%$ & $15.9 \pm 1.0 \S$ & $22.78 \pm 1.07 \dagger$ \\
\hline
\end{tabular}

$* P=.02$ versus control.

$\dagger P=.008$ versus control.

$\ddagger P=.006$ versus control.

$\S P=.046$ versus control.

desensitization of $\beta$-ARs (Table II). Importantly, this phenomenon was seen in both left and right ventricles. To further examine this apparent $\beta$-AR desensitization, we evaluated myocardial GRK activity and found an approximate 2-fold increase in GRK activity (Fig 5) in cytosolic fractions isolated from both ventricles $(P=$ .02 , Fig 5 ). This increase in GRK activity correlated with a significant increase in the myocardial content of BARK1 (Fig 6).

To examine sympathetic activation, we examined neuropeptide $\mathrm{Y}$ concentrations in samples of myocardium from both ventricles in the two groups ( $\mathrm{n}=3$ each). Decreases in myocardial neuropeptide $\mathrm{Y}$ concentrations reflect an increase in sympathetic activation as 


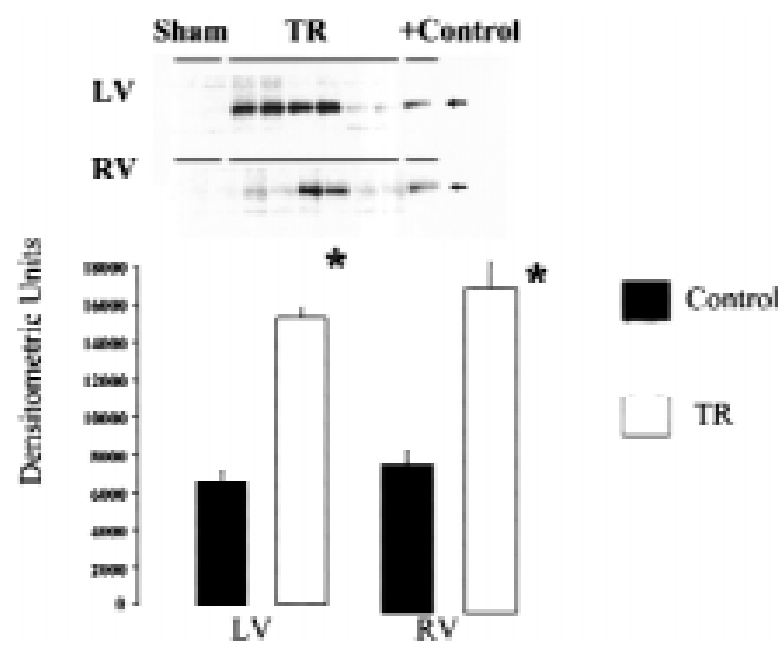

Fig 5. Summary of GRK activity (mean \pm SEM). A 2-fold elevation of GRK activity was seen in TR animals over control animals. Inset, A representative GRK rhodopsin phosphorylation assay from 3 animals with 1 week of TR compared with a sham-operated control animal and a positive control animal (arrow) for both the left and right ventricle of the respective dog. $* P<.02$ versus respective control animals.

neuropeptide $\mathrm{Y}$ is coreleased from sympathetic nerves. A significant biventricular decrease in myocardial neuropeptide $\mathrm{Y}$ concentration was seen in TR animals compared with control animals $(15.6 \pm 0.88 \mathrm{pg} / 100 \mu \mathrm{L}$ [TR right ventricle] and $11 \pm 2.5 \mathrm{pg} / 100 \mu \mathrm{L}$ [TR left ventricle] vs $25.3 \pm 1.8$ [control right ventricle] and $25.3 \pm 1.4$ [control left ventricle]; $P=.009$ ).

\section{Discussion}

In vivo function. The current study presents novel findings on the mechanical and molecular nature of early RV performance with an imposed volume load. The development and validation of the shell subtraction model has allowed practical in vivo measurement of $\mathrm{RV}$ volumes and the extension of load-insensitive measures of contractility to the study of RV function and interdependence with LV function. Alternately, the explosion in molecular cardiology has expanded our understanding of ventricular function. The SW versus EDV relationship is a well validated measure of contractile performance in the left ventricle, and work over the last 15 years has demonstrated its relative heart rate and afterload insensitivity. ${ }^{11}$ Karunanithi and colleagues ${ }^{4}$ and others ${ }^{14,15}$ rigorously confirmed that the PRSW relation could be applied to the right ventricle and was superior to a number of other indices of contractile function. The present study applied the PRSW

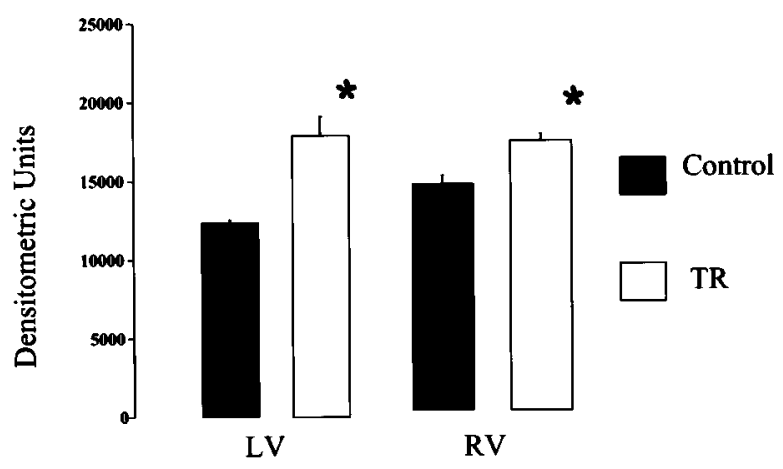

Fig 6. Specific protein immunoblotting reveals significant elevations of $\beta$ ARK1 myocardial protein content in animals with TR compared with sham-operated control animals (mean $\pm \mathrm{SEM}$ ). $* P<.02$ versus respective control animals.

analysis to a model of RV dysfunction to minimize confounding effects of RV preload and afterload inherent in TR.

Experimental work in RV dysfunction has centered on models of ischemia, decompensated failure, and pulmonary stenosis. ${ }^{2}$ Isolated TR appears to be a welltolerated state in canines. In long-term studies in dogs with TR induced by severing chordae over 1 to 3 years, overt right heart failure was only seen in animals with 3 years of TR, and animals at 1 year showed no significant alterations LV function. ${ }^{16}$

Clinical studies of patients with RV volume overload have presented a mixed picture. Several studies report preserved RV function in the face of long-standing TR or Ebstein anomaly. ${ }^{17-19}$ All of these studies, however, rely on load-dependent methods to determine function, particularly ejection fraction, and no study has examined the early effects of pathologic RV volume loading with autonomic blockade.

The current study demonstrated that acute and subacute volume overload caused a depression in contractile performance with dilatation of the right ventricle and elevations of EDP. The trend toward a rightward shift of the volume intercept suggests a measure of sarcomere rearrangement in response to the imposed volume load. ${ }^{20}$

Interestingly, experimental studies of LV volume overload have failed to show significant deterioration of chamber performance with early mitral regurgitation $^{21}$ or aortic regurgitation in canines. ${ }^{10}$ Autonomic activity appears to have significant role in compensation for LV failure and may account for some of the discrepancy in previous studies. Autonomic blockade was therefore used in this study to better characterize intrin- 
sic RV performance in the face of possible autonomic compensation. This study is among the first reports to observe that early RV and LV volume overload may differ in that RV volume overload is associated with an immediate and persistent decline in chamber function, whereas LV chamber function is preserved.

LV function was not directly evaluated in this particular study. As noted above, previous studies of TR in canines failed to demonstrate a significant reduction in LV performance at 1 year. Similarly, studies that directly address the issue of interdependence have demonstrated an enhancement of LV contractile function with acute elevations of RV afterload and decline in function because of RV volume overload. ${ }^{14,17}$ No previous study has examined LV function by using load-insensitive indices, and most studies, including this one, were performed with the pericardium open, which decreases direct ventricular interaction. Although severe TR in this model may depress cardiac output of the left ventricle, impairment of intrinsic LV performance is likely to be small.

$\beta$-AR alterations. A significant global depression of $\beta$-AR signaling was seen in animals with severe TR at 1 week compared with control animals. Previous studies in human heart failure have described a downregulation of $\beta$-AR density and functional uncoupling from second messenger systems. ${ }^{5}$ More recently, GRKs, in particular $\beta A R K 1$, have been found to mediate this uncoupling in human heart failure. ${ }^{22,23}$ Unique to the present study is that a pattern of biventricular uncoupling was seen in a model of compensated RV dysfunction but not overt failure. Importantly, we saw a significant increase in cytosolic GRK activity in TR animals, which can be attributed to the increased myocardial protein content of $\beta$ ARK $1 .^{24}$ This data suggests that GRK-mediated (ie, $\beta$ ARK1) desensitization is the mechanism for the functional $\beta$-AR uncoupling seen in this model of RV dysfunction. Thus, GRKmediated $\beta$-AR desensitization appears to be critically important in cardiovascular disease and consistent with our data in which $\beta$-AR-mediated AC activity was significantly depressed without loss of $\beta$-AR density. Although we did not measure $\beta$-AR subpopulations or G-protein subtypes, 1 week after the creation of RV volume overload is probably too early to see $\beta$-AR density changes, which is a late feature of chronic heart failure. Some of the alteration in AC activity may be accounted for by changes in G-protein subtypes. More important, however, 1 week was the time frame during which we uncovered changes in $\beta$ ARK1 and its effects on $\beta$-AR signaling. Our $\beta$-AR density data does not look at individual subtypes ( $\beta_{1}$ vs $\beta_{2}$ ), which may have changed in a reciprocal manner, but our signaling data suggests that other mechanisms besides receptor number are responsible for attenuated $\beta$-AR function.

Thus despite clinical compensentation, there appears to be global $\beta$-AR dysfunction with early RV volume overload. The exact mechanism of this molecular interdependence between the right and left ventricles is not elucidated in this study. However, central neurohormonal activation may account for biventricular desensitization. Larson and colleagues ${ }^{25}$ demonstrated elevations of plasma epinephrine and norepinephrine levels with 30 days of RV volume overload. Alternately, Bristow and associates ${ }^{26}$ postulated that local tissue factors and ventricular hypertrophy may play a role. We found a biventricular depression of myocardial concentrations of neuropeptide $Y$ and, in the absence of significant hypertrophy, suggests the role of a central catecholamine trigger in this model.

This global depression of $\beta$-AR signaling has multiple implications. First, it suggests that $\beta$ ARK1 and GRK activity are early molecular mediators during right heart dysfunction. The role of $\beta A R K 1$ and GRK activity in myocardial dysfunction has been previously demonstrated in mice where global $\beta A R K 1$ levels increased after chronic isoproterenol stimulation ${ }^{27}$ and alterations of myocardial $\beta$ ARK1 significantly affected in vivo LV contractile function..$^{22,28}$ Second, sustained abnormalities may predict and mediate progressive dysfunction and inotropic insensitivity. The present study provides novel and appealing targets for geneticbased treatment strategies, such as the inhibition of receptor desensitization with a $\beta$ ARK1 inhibitor. ${ }^{22,29}$ Future studies will help elucidate the duration and progression of $\beta$-AR abnormalities in right heart failure and dysfunction.

The present study is dependant on the shell-subtraction model to accurately estimate RV volumes and, although this has been validated in the normal canine myocardium, may not reflect alterations of chamber geometry caused by volume overload and chordae transection. Recent work by Waldman and colleagues ${ }^{30}$ demonstrated that longitudinal strains throughout the right ventricle vary with loading conditions. Preliminary sonomicrometric RV volume determinations with severe TR have correlated with volumes determined by 3dimensional echocardiography. ${ }^{31}$ Few alternative methods exist to practically determine dynamic pressure-volume relationships in conscious animals.

The current study is among the first to apply loadinsensitive indices of RV function in a chronic animal model of RV volume overload and to demonstrate concomitant global alterations of $\beta$-AR signaling. By using 
the shell subtraction model for RV volume determination, a significant reduction in chamber contractility was demonstrated in RV volume overload. This study confirmed previously reported biventricular $\beta$-AR signaling abnormalities with isolated RV dysfunction. ${ }^{8,9}$ However, our changes occurred earlier than previously reported and were found for the first time to be associated with enhanced GRK activity mediated by $\beta$ ARK1. This provides further evidence of potential targets for cardiac gene therapy. These findings demonstrate fundamental differences of RV behavior with respect to the left ventricle and provide new insight into mechanisms of early RV dysfunction.

We thank Ruth Rogers and Kyle Shotwell for technical assistance.

\section{REFERENCES}

1. Rigolin VH, Robiolio PA, Wilson JS, Harrison JK, Bashore TM. The forgotton chamber: the importance of the right ventricle. Cathet Cardiovasc Diagn 1995;35:18-28.

2. Santamore WP, Dell'Italia LJ. Ventricular interdependance: Signifigant left ventricular contributions to right ventricular systolic function. Prog Cardiovasc Dis 1998;40:289-308.

3. Maughan WL, Shoukas AA, Sagawa K, Weisfeldt ML. Instantaneous pressure-volume relationship in the canine right ventricle. Circ Res 1970;44:309-15.

4. Karunanithi MK, Michniewicz J, Copeland S, Feneley MP. Right ventricular preload recruitable stroke work, end-systolic pressure-volume relations, and $\mathrm{dP} / \mathrm{dtmax}$-end-diastolic volume relations compared as indices of right ventricular contractile performance in conscious dogs. Circ Res 1992;70:1169-79.

5. Bristow MR, Ginsburg R, Minobe W, Cubiciotti RS, Sageman WS, Lurie K, et al. Decreased catecholamine sensitivity and $\beta$ adrenergic density in failing human hearts. $\mathrm{N}$ Engl $\mathrm{J}$ Med 1982;307:205-11.

6. Lohse MJ, Engelhardt S, Danner S, Bohm M. Mechanisms of $\beta$ adrenergic receptor desensitization: from molecular biology to heart failure. Basic Res Cardiol 1996;91:29-34.

7. Maurice JP, Shah AS, Kypson AP, Hata J, White DC, Glower DD, et al. Molecular $\beta$-adrenergic signaling abnormalities in failing rabbit hearts after infarction. Am J Physiol 1999;276:H1853-60.

8. Fan TH, Liang CS, Kawashima S, Banerjee SP. Alterations of $\beta$ adrenoreceptor responsiveness and adenylate cyclase system by congestive heart failure in dogs. Eur J Pharmacol 1987;140:12332.

9. Liang CS, Frantz RP, Suematsu M, Sakamoto S, Sullebarger JT, Fan TM, et al. Chronic $\beta$-adrenoreceptor blockade prevents the development of $\beta$-adrenergic subsensitivity in experimental rightsided congestive heart failure in dogs. Circulation 1991;84:25466.

10. Gaynor JW, Feneley MP, Gall SA, Savitt MA, Silvestry SC, Davis JW, et al. Left ventricular adaptation to aortic regurgitation in conscious dogs. J Thorac Cardiovasc Surg 1997;113:149-58.

11. Glower DD, Spratt JA, Snow ND, Kabas JS, Davis JW, Olsen $\mathrm{CO}$, et al. Linearity of the Frank-Starling relationship in the intact heart: the concept of preload recruitable stroke work. Circulation 1985;71:994-1009.
12. Glower DD, Spratt J, Kabas JS, Davis, JW, Rankin JS. Quantification of regional myocardial dysfunction after acute ischemic injury. Am J Physiol 1988;255:H85-93.

13. Akhter SA, Skaer CA, Kypson AP, McDondald PH, Peppel KC, Glower DD, et al. Restoration of $\beta$-adrenergic signaling infiling cardiac ventricular myocytes via adenoviral mediated gene transfer. Proc Natl Acad Sci U S A 1997;94:12100-5.

14. Feneley MP, Olsen CO, Glower DD, Rankin JS. Effect of acutely increased afterload on work output from the left ventricle in conscious dogs. Circ Res 1989;65:135-45.

15. Feneley MP, Elbeery JR, Gaynor JW, Gall SA, Davis JW, Rankin JS. Ellipsoidal shell subtraction model of right ventricular volume: Comparison with regional free wall dimensions as indexes of right ventricular function. Circ Res 1990;67:1427-36.

16. Bauman RP, Remebert JC, Greenfield JC. Myocardial blood flow in awake dogs with chronic tricuspid regurgitation. Basic Res Cardiol 1998;93:63-9.

17. Louie EK, Lin SS, Reynertson SI, Brundage BH, Levitsky S, Rich S. Pressure and volume loading of the right ventricle have opposite effects on left ventricular ejection fraction. Circulation 1995;92:819-24.

18. Saxena A, Fong LV, Tristam M, Ackery DM, Keeton BR. Late noninvasive evaluation of cardiac performance in mildly symptomatic older patients with Ebstein's anomaly of tricuspid valve: role of radionuclide imaging. J Am Coll Cardiol 1991;17:182-6.

19. Vatterott PJ, Nishimura RA, Gersh BJ, Smith HC. Severe isolated tricuspid insufficiency in coronary artery disease. Int J Cardiol 1987; 14:295-301.

20. Glower DD, Schaper J, Kabas JS, Hoffmeister HM, Schaper W, Spratt JA, et al. Relation between reversal of diastolic creep and recovery of systolic function after ischemic myocardial injury in conscious dogs. Circ Res 1987;60:850-60.

21. Atkins BZ, Shah AS, Lilly RE, Silvestry SC, Davis JW, Glower DD. Left ventricular energetics in pacing induced and failure and mitral regurgitation: preservation of chemomechanical coupling in canines with mitral regurgitation. Circulation 1998;98 (Suppl):I-254.

22. Koch WJ, Rockman HA, Samama P, Hamilton RA, Bond RA, Milano CA, et al. Cardiac function in mice overexpressing the $\beta$-adrenergic kinase or a $\beta$ ARK inhibitor. Science 1995;268: 1350-3.

23. Ungerer M, Bohm M, Elce JS, Erdmann E, Lohse ML. Altered expression of $\beta$-adrenergic receptor kinase and $\beta 1$-adrenergic receptors in heart failure. Circulation 1993;87:454-63.

24. Choi D-J, Koch WJ, Hunter JJ, Rockman. Mechanism for $\beta$ adrenergic receptor desensitization in cardiac hypertrophy is increased $\beta$-adrenergic receptor kinase. J Biol Chem 1997;272: 17223-9.

25. Larson DF, Womble JR, Copeland JG, Russell DH. Concurrent left and right ventricular hypertrophy in dog models of right ventricular overload. J Thorac Cardiovasc Surg 1982;84:543-7.

26. Bristow MR, Minobe W, Rasmussen R, Larrabee P, Skerl L, Klein J, et al. $\beta$-adrenergic neuroreffector mechanisms in the failing human heart are produced by local rather than systemic mechanisms. J Clin Invest 1992;89:803-15.

27. Iaccarino G, Tomhave ED, Lefkowitz RJ, Koch WJ. Reciprocal in vivo regulation of myocardial $G$ protein-coupled receptor kinase expression by $\beta$-adrenergic receptor stimulation and blockade. Circulation 1998;98:1783-9.

28. Rockman HA, Choi DJ, Akhter SA, Jaber M, Giros B, Lefkowitz 
$\mathrm{RJ}$, et al. Control of myocardial contractile function by the level of $\beta$-adrenergic receptor kinase 1 in gene-targeted mice. J Biol Chem 1998;273:18180-4.

29. Rockman HA, Chien KR, Choi D, Iaccarino G, Hunter JL, Ross $\mathrm{J}$, et al. Expression of a $\beta$-adrenergic receptor kinase 1 inhibitor prevents the devlopment of myocardial failure in gene-targeted mice. Proc Natl Acad Sci U S A 1998;95:7000-5.
30. Waldman LK, Allen JJ, Pavelec RS, McCulloch AD. Distributed mechanics of the canine right ventricle: effects of varying preload. J Biomech 1996;29:373-81.

31. Shu M, Shah AS, Atkins BZ, Smith PK, Glower DD, Pasipoularides AD. Diastolic right ventricular flow: increased symmetry in volume overload with paradoxical septal motion. Circulation 1998;98(Suppl):I-844.

\section{Online-www.aats.org}

Now you can get The Journal of Thoracic and Cardiovascular Surgery online. The Journal online brings you faster delivery time, easy searching of current and back issues, links to PubMed, AATS, WTSA, and other important sites, and more. Visit the Journal online today.

\section{Receive tables of contents by e-mail}

To receive the tables of contents by e-mail, sign up through our Web site at http://www.mosby.com/jtcvs. Choose E-mail Notification. Simply type your e-mail address in the box and click the Subscribe button.

Alternatively, you may send an e-mail message to majordomo@mosby.com. Leave the subject line blank and type the following as the body of your message: subscribe jtcvs_toc.

You will receive an e-mail to confirm that you have been added to the mailing list. Note that table of contents e-mails will be sent out when a new issue is posted to the Web site. 